\title{
Rhinitis, sinusitis and ocular disease - 2039. Effect of intranasal steroid on cough symptom in patients with upper airway couth syndrome
}

\author{
Jeong-Eun Kim*, Jun-Hwi Song, Kyeung-Woo Kang \\ From 2nd WAO International Scientific Conference (WISC 2012) \\ Hyderabad, India. 6-9 December 2012
}

\section{Background}

Upper airway cough syndrome (UACS) with rhinosinusitis is a major cause of chronic cough. Little is, however, known about the effects of medications used for chronic rhinosinusitis on symptom improvement in patients with chronic cough. The objective of this study is to observe outcome difference according to the medications used in patients with chronic cough caused by UACS.

\section{Methods}

Medical records of patients, who visited our clinic for chronic cough caused by UACS from Jan 2011 to May 2012, were reviewed retrospectively. Patients with other diseases including bronchial asthma, gastroesophageal reflux disorder, and eosinophilic bronchitis were excluded. The medications and the results of paranasal sinus (PNS) series at $1^{\text {st }}$ visit were evaluated. According to the improvement of cough at $2^{\text {nd }}$ visit, the patients were divided into improved (no or a few cough) and not improved (no or a little improvement) groups. The effects of medications on cough were analyzed by multivariate logistic regression.

\section{Results}

The medications at $1^{\text {st }}$ visit were composed of antihistamines, decongestants, antibiotics, leukotriene antagonists, and intranasal steroids. All the patients were treated with antitussives. The number of patients who used intranasal steroids was higher in improved group than in not improved group. Intranasal steroids were the only medication to improve cough significantly (OR 3.4, 95\% CI [1.110.2], $p=0.033)$, which was more significant in patients

Department of Internal Medicine, Samsung Changwon Hospital, Sungkyunkwan University School of Medicine, Changwon, South Korea with chronic rhinosinusitis finding on PNS (OR 15.7, 95\% CI [2.0-124.7], $p=0.009$ ).

\section{Conclusions}

Intranasal steroid use may be beneficial to improve cough symptom in patients with UACS, in particular those with chronic rhinosinusitis finding on PNS.

Published: 23 April 2013

doi:10.1186/1939-4551-6-S1-P171

Cite this article as: Kim et al:: Rhinitis, sinusitis and ocular disease 2039. Effect of intranasal steroid on cough symptom in patients with upper airway couth syndrome. World Allergy Organization Journal 2013 6(Suppl 1):P171.
Submit your next manuscript to BioMed Central and take full advantage of:

- Convenient online submission

- Thorough peer review

- No space constraints or color figure charges

- Immediate publication on acceptance

- Inclusion in PubMed, CAS, Scopus and Google Scholar

- Research which is freely available for redistribution 